\title{
A comparison of medley and freestyle performance for national and international swimmers between I 994 and 20II
}

This article was published in the following Dove Press journal:

Open Access Journal of Sports Medicine

25 March 2013

Number of times this article has been viewed

Christof Buhl'

Beat Knechtle ${ }^{1,2}$

Christoph Alexander Rüst ${ }^{1}$

Thomas Rosemann'

Romuald Lepers ${ }^{3}$

'Institute of General Practice and for Health Services Research, University of Zurich, Zurich, Switzerland;

${ }^{2}$ Gesundheitszentrum St Gallen, St Gallen, Switzerland; ${ }^{3}$ Faculty of Sport Sciences, University of Burgundy, Dijon, France
Correspondence: Beat Knechtle Facharzt FMH für Allgemeinmedizin, Gesundheitszentrum St Gallen, Vadianstrasse 26, St Gallen 900I, Switzerland

Tel +4I 7| 2268282

$\mathrm{Fax}+4|7| 2268272$

Email beat.knechtle@hispeed.ch
Abstract: The change in swim performance over time has been investigated for freestyle, but not for other strokes, such as in the medley. The aim of the study was to examine changes in $200 \mathrm{~m}$ and $400 \mathrm{~m}$ swim performances in medley swimmers at national (Switzerland) and international level (world championship finals) from 1994 to 2011. The $200 \mathrm{~m}$ and $400 \mathrm{~m}$ freestyle performances were also analyzed for comparison. Swim performances were analyzed using linear regression and one-way analysis of variance. Male Swiss swimmers improved swim speed by $5.4 \%$ in the $200 \mathrm{~m}$ medley, $5.3 \%$ in the $200 \mathrm{~m}$ freestyle, $5.1 \%$ in the $400 \mathrm{~m}$ medley, and $5.7 \%$ in the $400 \mathrm{~m}$ freestyle $(P<0.01)$. Female Swiss swimmers improved swim speed by $4.4 \%$ in the $200 \mathrm{~m}$ medley, $3.3 \%$ in the $200 \mathrm{~m}$ freestyle, $3.9 \%$ in the $400 \mathrm{~m}$ medley, and $3.4 \%$ in the $400 \mathrm{~m}$ freestyle $(P<0.05)$. Male swimmers at international level improved swim speed by $4.5 \%$ in the $200 \mathrm{~m}$ medley, $4.6 \%$ in the $200 \mathrm{~m}$ freestyle, $2.6 \%$ in the $400 \mathrm{~m}$ medley, and $2.7 \%$ in the $400 \mathrm{~m}$ freestyle $(P<0.01)$. Female swimmers improved swim speed by $4.3 \%$ in the $200 \mathrm{~m}$ medley, $3.5 \%$ in the $400 \mathrm{~m}$ medley, and $3.1 \%$ in the $400 \mathrm{~m}$ freestyle $(P \leq 0.02)$, but $200 \mathrm{~m}$ freestyle performance remained unchanged $(P>0.05)$. The sex difference in national swim performance remained unchanged at $10.2 \% \pm 0.6 \%$ for the $200 \mathrm{~m}$ medley $(P>0.05)$ and increased from $8.8 \%$ to $9.8 \%$ for the $400 \mathrm{~m}$ medley $(P<0.05)$. In freestyle, it increased from $8.8 \%$ to $10.7 \%$ in the $200 \mathrm{~m}$, and from $7.8 \%$ to $9.4 \%$ in the $400 \mathrm{~m}(P<0.01)$. The sex difference in international athletes remained unchanged at $11.1 \% \pm 0.9 \%$ in the $200 \mathrm{~m}$ medley, $10.1 \% \pm 0.8 \%$ in the $400 \mathrm{~m}$ medley, $10.0 \% \pm 1.3 \%$ in the $200 \mathrm{~m}$, and $9.2 \% \pm 0.6 \%$ in the $400 \mathrm{~m}$ freestyle $(P>0.05)$. For the $400 \mathrm{~m}$ medley, the sex difference was lower compared to the $200 \mathrm{~m}$ medley for national $(9.3 \% \pm 0.8 \%$ vs $10.2 \% \pm 0.6 \%, P=0.01)$ and for international $(10.1 \% \pm 0.8 \%$ vs $11.1 \% \pm 0.9 \%)$ athletes. For the $400 \mathrm{~m}$ freestyle, the sex difference was lower compared to the $200 \mathrm{~m}$ freestyle for national $(7.9 \% \pm 0.9 \%$ vs $9.3 \% \pm 0.8 \%)$ and international $(9.2 \% \pm 0.6 \%$ vs $10.0 \% \pm 1.3 \%)$ athletes $(P<0.01)$, and lower in the freestyle than the medley for the same distances $(P<0.01)$. Future studies should investigate the reasons for the greater sex difference in the medley than the freestyle.

Keywords: men, women, athlete, swimming

\section{Introduction}

The general goal in competitive short-, middle-, and long-distance sports, such as running, cycling, and swimming, is to finish a given distance in the shortest possible time. Several studies investigated the performance trends in different Olympic disciplines by analyzing the development of world records across years. ${ }^{1-4}$ The development of world records in endurance disciplines, such as cycling, speed skating, triathlon, running, and swimming showed a decrease in race times during the last century. ${ }^{1,4,5}$ This improvement temporarily stopped or reached a plateau in the 1970 s in running, ${ }^{1,3}$ swimming, and cycling. ${ }^{1}$ In contrast, for a younger sport, such as triathlon, the improvement plateaued 
in the 1990s. ${ }^{5}$ Berthelot et al suggested that the maximum possible physiological sports performance in human species will be reached in one generation and predicted that half of all world records will not be improved more than $0.05 \%$ in $2027 .^{1}$

A historical comparison of female and male world records in different disciplines during the twentieth century showed a nearly doubled higher relative improvement of athletic performance in women compared to men. ${ }^{3,6}$ Beneke et al predicted that women would decrease the sex difference or even be faster than men in long-distance running. ${ }^{7}$ Thibault et al investigated world record progression in Olympic events over the 1891-2008 period for 26 athletics events and over the 1963-2008 period for 24 swimming events. ${ }^{4}$ They showed that the sex difference in world records in the Olympic running and swimming disciplines decreased from $\sim 30 \%$ in running and $\sim 23 \%$ in swimming at the beginning of the twentieth century to $\sim 11 \%$ in running and $\sim 9 \%$ in swimming in the 1980 s. Afterwards, the sex difference remained stable until 2008. The conclusion was that women may never outrun men.

For freestyle swimming, Nevill et al reported an "accelerated" improvement by $0.010 \mathrm{~m} / \mathrm{second}$ per year for men and by $0.015 \mathrm{~m} / \mathrm{second}$ per year for women in the development of world records during the 1960s and 1970 s. $^{2}$ During the 1980 s and 1990 s, there was a plateau of performance, suggesting that the limits to swimming world records were almost reached. The sex difference in $100 \mathrm{~m}$ freestyle performance was $12 \%$ in $1957,10 \%$ in 1981 , and $11 \%$ in $2006 .^{2}$ Another study investigated the sex difference of the top six finishers in Olympic and world championship finals in the $100 \mathrm{~m}$ freestyle and backstroke between 1952 and $2006 .^{8}$ In accordance with the development of world records in freestyle, ${ }^{2}$ the sex difference in the $100 \mathrm{~m}$ freestyle decreased from $14.3 \%$ in the 1950 s to $11.5 \%$ in the $1980 \mathrm{~s}$, and was stable until the year 2000 . However, contrary to the expectations of stagnation and an almost reached maximum physiologically possible sports performance, ${ }^{1}$ the swim times in the different strokes had been improved again in the 2000 s by $\sim 2 \%,{ }^{9}$ and the sex difference in the $100 \mathrm{~m}$ freestyle increased again to $12.2 \%$ between 2000 and $2005 .^{8}$ This improvement could be partially explained by the development of the new drag-reducing swimsuits in 2000, 2008, and $2009,{ }^{9}$ improved pool designs like deeper pools and more effective "antiwave" lane ropes, ${ }^{10}$ a more efficient training process based on better training control with, eg, the robotic underwater camcorder, ${ }^{10}$ and also a better evaluation of swimmers by physiological parameters, psychological skills, and emotional competencies. ${ }^{11}$
The development of swim speed, ${ }^{9,12,13}$ as well as the sex difference across the years, ${ }^{2,4,8,12,13}$ has been investigated in freestyle ${ }^{2,8,12,13}$ and backstroke. ${ }^{8}$ In another study investigating all five competitive swim disciplines - freestyle, backstroke, breaststroke, butterfly, and individual medley - the gain in swim speed related to the introduction of the new generations of swimsuits in 2000, 2008, and 2009. ${ }^{9}$ A further study investigated the sex difference in the five competitive swim disciplines, but focused on the mean sex difference in swimming across years. ${ }^{4}$

To the best of our knowledge, the present study is the first to focus on the change in individual medley swim performance for both men and women across years. The first aim of this study was to investigate the changes in $200 \mathrm{~m}$ and $400 \mathrm{~m}$ individual medley swim speed for both female and male Swiss swimmers at national level and the international elite competing in the finals at the world championships from 1994 to 2011 . The $200 \mathrm{~m}$ and $400 \mathrm{~m}$ freestyle were analyzed as an internal control and compared to the existing literature. The second aim was to analyze the change in sex difference in swim speed over this studied period for both individual medley and freestyle. We hypothesized, firstly, an improvement in swim speed for both disciplines across the years, and secondly a stability of sex differences in swim performance over the 1994-2011 period.

\section{Materials and methods}

The annual top ten freestyle and individual medley performances for both female and male elite Swiss swimmers and the top eight performances from the world championship finals between 1994 and 2011 on the $50 \mathrm{~m}$ long course were analyzed in the $200 \mathrm{~m}$ and $400 \mathrm{~m}$ distances. The data set from this study was obtained from the website of the Swiss Swimming Federation ${ }^{14}$ and from the website recording information from the European Swimming Federation rankings database. ${ }^{15}$ The study was approved by the Institutional Review Board of St Gallen, Switzerland, with waiver of the requirement for informed consent, given that the study involved the analysis of publicly available data.

\section{Data analysis}

In total, data were available from 1994 to 2011 for 144 swim meetings in annual Swiss championships and for 64 finals in the world championships held in the years 1994, 1998, 2001, 2003, 2005, 2007, 2009, and 2011. No athlete was included more than once for Swiss swimmers in the same year, because Swiss Swimming Federation lists only the annual best performance of an athlete in the same year. 
We present the trend of swim speed for the annual best performances of the top ten swimmers in Swiss championships and the top eight swimmers in the finals in the world championship between 1994 and 2011 for both the $200 \mathrm{~m}$ and $400 \mathrm{~m}$ individual medley and freestyle. Swim times were transformed to swim speed using the equation (swim distance in meters)/(swim time in seconds). To compare women and men, the sex difference was calculated using the equation ([swim speed in women] - [swim speed in men $] /([$ swim speed in men $] \times 100)$. To facilitate the reading of the figures, all sex differences were transformed to absolute values. Afterwards, these data were analyzed regarding differences in swim speed between sexes as well as development of the annual performance of the highest swim speed between 1994 and 2011.

\section{Statistical analysis}

In order to increase the reliability of data analyses, each set of data was tested for normal distribution as well as for homogeneity of variances in advance of statistical analyses. Normal distribution was tested using a D'Agostino and Pearson omnibus normality test and homogeneity of variances was tested using Levene's test. To find significant changes in the development of a variable across years, linear regression was used to investigate the trend over time. One-way analysis of variance was used to analyze differences between sex difference in individual medley versus freestyle performance for both $200 \mathrm{~m}$ and $400 \mathrm{~m}$. Statistical analyses were performed using SPSS Statistics (version 19; IBM, Chicago, Armonk, NY, USA) and GraphPad Prism (version 5; GraphPad Software, La Jolla, CA, USA) software. Significance was accepted at $P<0.05$ (two-sided for $t$-tests). Data in the text are given as means \pm standard deviation.

\section{Results}

\section{Changes in swim speed in medley and freestyle across the years}

Elite Swiss swimmers of both sexes improved swim speed across the years (Table 1) in the individual medley for both $200 \mathrm{~m}$ (Figure 1A) and $400 \mathrm{~m}$ (Figure 2A) and in freestyle for $200 \mathrm{~m}$ (Figure 3A) and $400 \mathrm{~m}$ (Figure 4A). International elite swimmers at the world championships improved swim speed (Table 2) in the medley for $200 \mathrm{~m}$ (Figure 1B) and $400 \mathrm{~m}$ (Figure 2B). International elite swimmers improved swim speed in freestyle for the $200 \mathrm{~m}$ (Figure 3B) and $400 \mathrm{~m}$ (Figure 4B), but the women's $200 \mathrm{~m}$ freestyle remained unchanged.
Table I Change in mean swim speed in national swimmers from 1994 to 201 I for women and men

\begin{tabular}{|c|c|c|c|c|}
\hline \multirow[t]{2}{*}{$\begin{array}{l}\text { National } \\
\text { championships }\end{array}$} & \multicolumn{2}{|c|}{$\begin{array}{l}\text { Mean swim speed } \\
\text { (m/second) }\end{array}$} & \multirow[t]{2}{*}{$\begin{array}{l}\text { Change } \\
(\%)\end{array}$} & \multirow[t]{2}{*}{ Significance* } \\
\hline & 1994 & 2011 & & \\
\hline \multicolumn{5}{|l|}{ Women } \\
\hline $200 \mathrm{~m}$ freestyle & $1.54 \pm 0.02$ & $1.59 \pm 0.02$ & +3.3 & $P<0.01$ \\
\hline $400 \mathrm{~m}$ freestyle & $1.47 \pm 0.02$ & $1.52 \pm 0.02$ & +3.4 & $P=0.03$ \\
\hline 200 m medley & $1.35 \pm 0.03$ & $\mathrm{I} .4 \mathrm{I} \pm 0.03$ & +4.4 & $P<0.01$ \\
\hline 400 m medley & $1.28 \pm 0.02$ & $1.33 \pm 0.03$ & +3.9 & $P<0.01$ \\
\hline \multicolumn{5}{|l|}{ Men } \\
\hline $200 \mathrm{~m}$ freestyle & $1.69 \pm 0.01$ & $1.78 \pm 0.04$ & +5.3 & $P<0.01$ \\
\hline $400 \mathrm{~m}$ freestyle & $1.59 \pm 0.03$ & $1.68 \pm 0.03$ & +5.7 & $P<0.01$ \\
\hline 200 m medley & $1.48 \pm 0.02$ & $1.56 \pm 0.02$ & +5.4 & $P<0.01$ \\
\hline 400 m medley & $1.38 \pm 0.04$ & $1.45 \pm 0.02$ & +5.1 & $P<0.01$ \\
\hline
\end{tabular}

Note: *Significance refers to linear regression analysis of mean swim speed across years. Results are presented as mean and standard deviation (SD). Abbreviation: $\mathrm{m}$, meters.

\section{Changes in sex difference in swim speed across the years}

The sex difference in swim speed increased in the $200 \mathrm{~m}$ and $400 \mathrm{~m}$ freestyle and in the $400 \mathrm{~m}$ medley, but remained unchanged in the $200 \mathrm{~m}$ medley at the national championships (Table 3). At the world championships, the sex difference in swim speed remained unchanged over time in freestyle and medley for both the $200 \mathrm{~m}$ and $400 \mathrm{~m}$ (Table 3).

\section{Sex difference in medley and freestyle performance}

The sex difference in swim speed in elite national swimmers in the $400 \mathrm{~m}$ medley was equal to $9.3 \% \pm 0.8 \%$ and was significantly lower $(P<0.01)$ compared to the $200 \mathrm{~m}$ medley $(10.2 \% \pm 0.6 \%)$ (Figure $5 \mathrm{~A})$. Similarly, the mean sex difference in swim speed in the $400 \mathrm{~m}$ freestyle was equal to $7.9 \% \pm 0.9 \%$ and was significantly lower $(P<0.01)$ compared to swim speed in the $200 \mathrm{~m}$ freestyle $(9.3 \% \pm 0.8 \%)$. The mean sex difference in swim speed in the $400 \mathrm{~m}$ medley was significantly higher $(P<0.01)$ compared to the $400 \mathrm{~m}$ freestyle. Similarly, the mean sex difference in swim speed in the $200 \mathrm{~m}$ medley was significantly higher $(P<0.01)$ compared to the $200 \mathrm{~m}$ freestyle.

The sex difference in swim speed in international elite athletes in the $400 \mathrm{~m}$ medley was equal to $10.1 \% \pm 0.8 \%$ and was significantly lower $(P<0.01)$ compared to the $200 \mathrm{~m}$ medley $(11.1 \% \pm 0.9 \%)$ (Figure 5B). Similarly, the mean sex difference in swim speed in the $400 \mathrm{~m}$ freestyle was equal to $9.2 \% \pm 0.6 \%$ and significantly lower $(P<0.01)$ compared to swim speed in the $200 \mathrm{~m}$ freestyle $(10.0 \% \pm 1.3 \%)$. The sex difference in swim speed in the $400 \mathrm{~m}$ medley was significantly higher $(P<0.01)$ compared to the $400 \mathrm{~m}$ freestyle. 

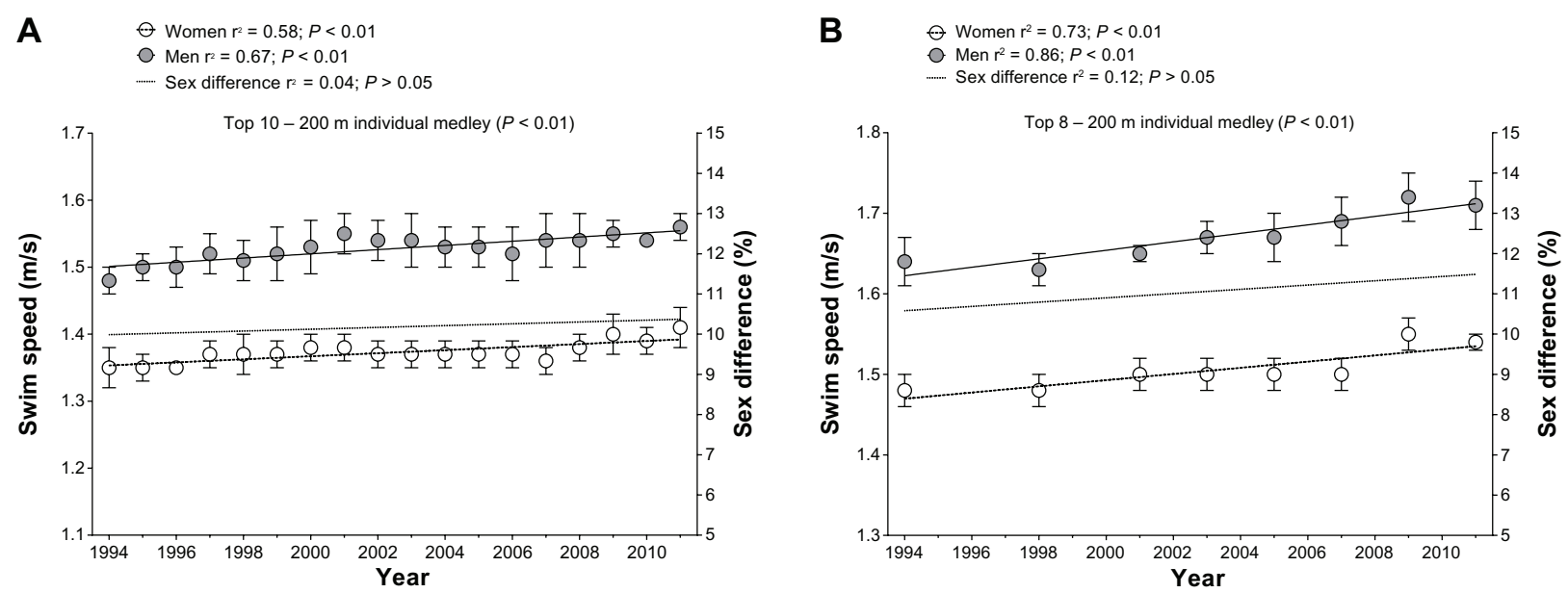

Figure I Changes in swim speed of the annual top ten elite Swiss (A) and of the top eight of the world championship (B) medley swimmers of both sexes with sex difference in performance from 1994 to $201 \mathrm{I}$ for $200 \mathrm{~m}$.
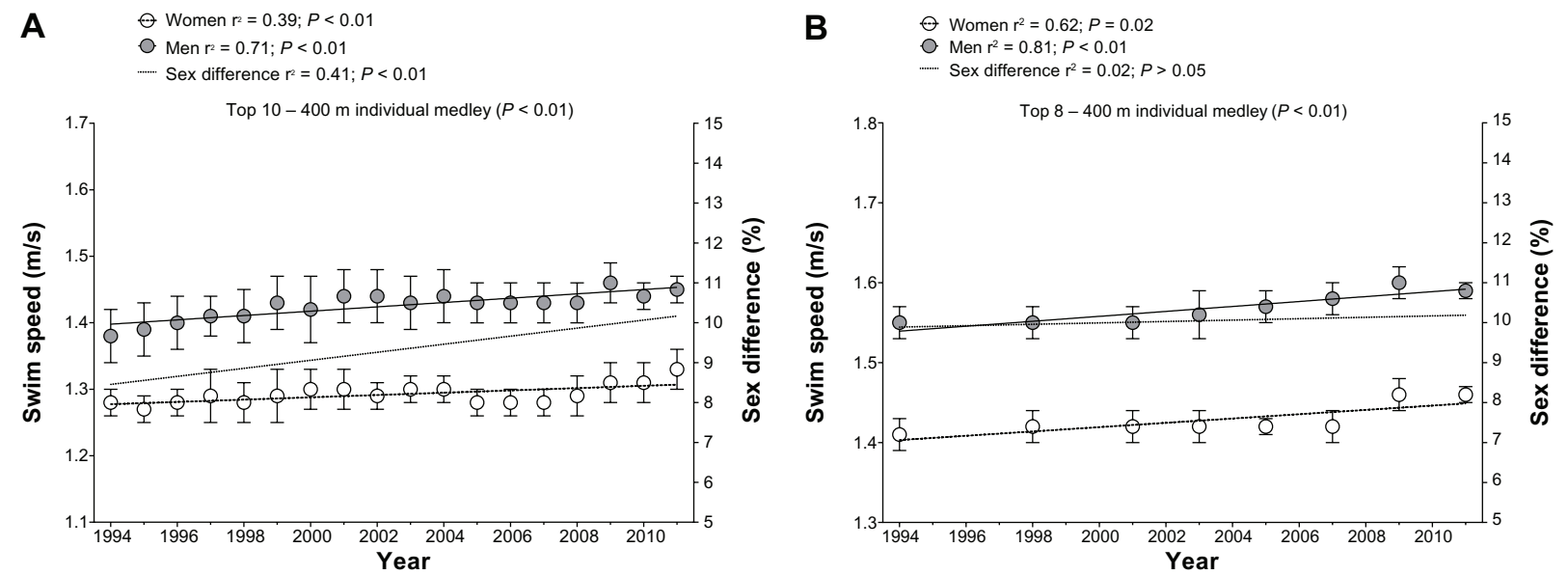

Figure 2 Changes in swim speed of the annual top ten elite Swiss $(\mathbf{A})$ and of the top eight of the world championship (B) medley swimmers of both sexes with sex difference in performance from 1994 to $20 \mathrm{II}$ for $400 \mathrm{~m}$.
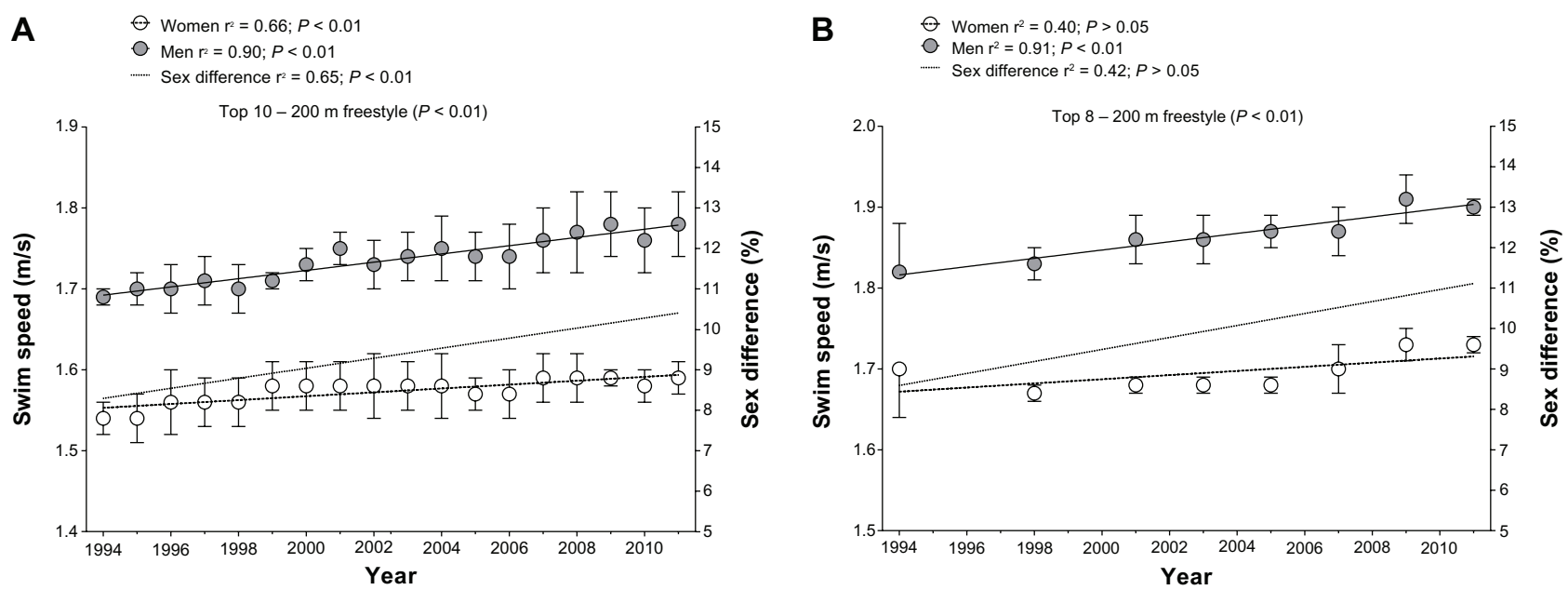

Figure 3 Changes in swim speed of the annual top ten elite Swiss $(\mathbf{A})$ and of the top eight of the world championship (B) freestyle swimmers of both sexes with sex difference in performance from 1994 to $201 \mathrm{I}$ for $200 \mathrm{~m}$. 

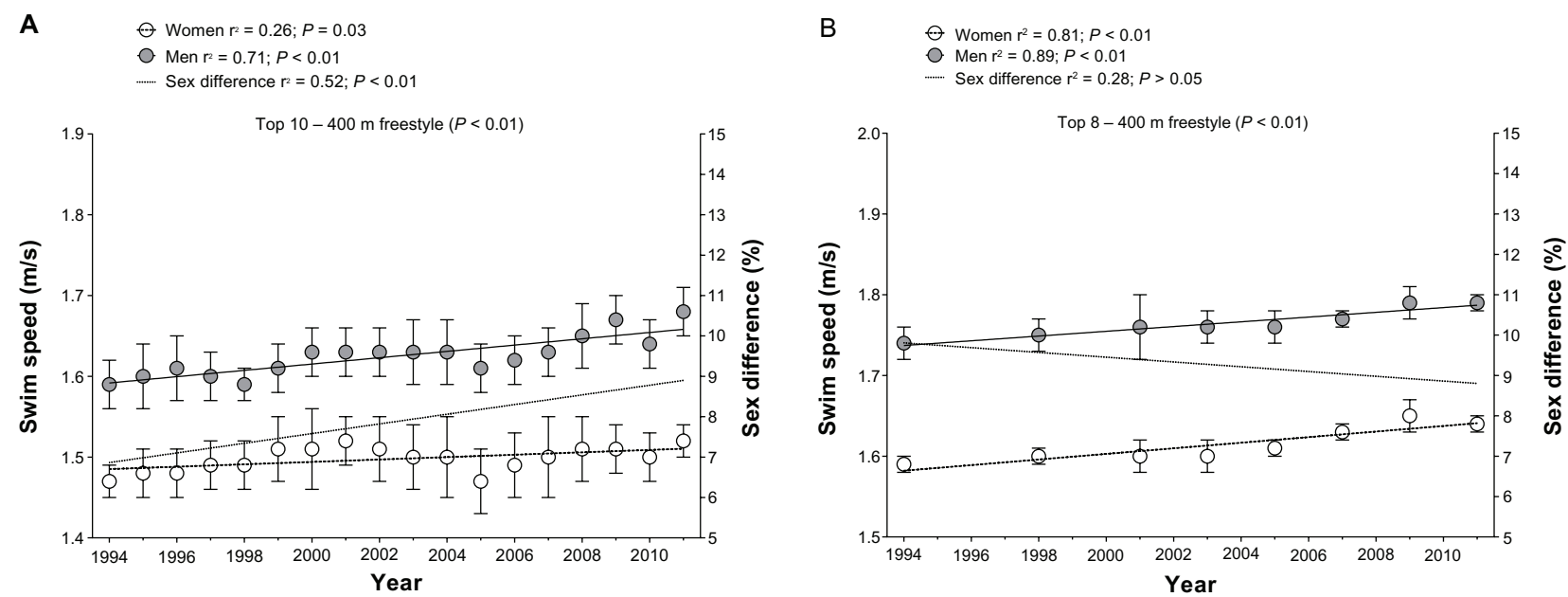

Figure 4 Changes in swim speed of the annual top ten elite Swiss (A) and of the top eight of the world championship (B) freestyle swimmers of both sexes with sex difference in performance from 1994 to $201 \mathrm{I}$ for $400 \mathrm{~m}$.

The sex difference in swim speed in the 200 m medley was significantly higher $(P<0.01)$ compared to the $200 \mathrm{~m}$ freestyle.

\section{Discussion}

The main findings of this study were (1) an improvement of swim speed in the $200 \mathrm{~m}$ and $400 \mathrm{~m}$ individual medley and freestyle for both men and women during the 1994-2011 period in swimmers at national level originating from Switzerland and similarly in swimmers in the finals in the world championships, with one exception of an unchanged swim-speed performance in the $200 \mathrm{~m}$ freestyle in women in the world championship, (2) a stability in the sex difference in swim speed in both disciplines and distances in the world championships and in the $200 \mathrm{~m}$ medley in national athletes

Table 2 Change in mean swim speed at world championships from 1994 to 201 I for women and men

\begin{tabular}{|c|c|c|c|}
\hline \multirow[t]{2}{*}{$\begin{array}{l}\text { World } \\
\text { championships }\end{array}$} & $\begin{array}{l}\text { Mean swim speed } \\
\text { (m/second) }\end{array}$ & \multirow[t]{2}{*}{$\begin{array}{l}\text { Change } \\
\text { (\%) }\end{array}$} & \multirow[t]{2}{*}{ Significance* } \\
\hline & 1994 & & \\
\hline
\end{tabular}

\section{Women}

$\begin{array}{lrrrl}200 \mathrm{~m} \text { freestyle } & 1.7 \pm 0.06 & 1.73 \pm 0.01 & +1.7 & P>0.05 \\ 400 \mathrm{~m} \text { freestyle } & 1.59 \pm 0.01 & 1.64 \pm 0.01 & +3.1 & P<0.01 \\ 200 \mathrm{~m} \text { medley } & 1.48 \pm 0.02 & 1.54 \pm 0.01 & +4.3 & P<0.01 \\ 400 \mathrm{~m} \text { medley } & 1.41 \pm 0.02 & 1.46 \pm 0.01 & +3.5 & P=0.02 \\ \text { Men } & & & & \\ 200 \mathrm{~m} \text { freestyle } & 1.82 \pm 0.06 & 1.90 \pm 0.01 & +4.6 & P<0.01 \\ 400 \mathrm{~m} \text { freestyle } & 1.74 \pm 0.02 & 1.79 \pm 0.01 & +2.7 & P<0.01 \\ 200 \mathrm{~m} \text { medley } & 1.64 \pm 0.03 & 1.71 \pm 0.03 & +4.5 & P<0.01 \\ 400 \mathrm{~m} \text { medley } & 1.55 \pm 0.02 & 1.59 \pm 0.01 & +2.6 & P<0.01\end{array}$

Note: *Significance refers to linear regression analysis of mean swim speed across years. Results are presented as mean and standard deviation (SD).

Abbreviation: $\mathrm{m}$, meters. originating from Switzerland, while sex difference in swim speed in national championships increased in the $400 \mathrm{~m}$ medley and in both the $200 \mathrm{~m}$ and $400 \mathrm{~m}$ freestyle across the years, and (3) a higher sex difference in swim speed in medley compared to freestyle over the same distances in both national athletes and international athletes.

\section{Improvement of swim speed across the years}

Elite Swiss swimmers of both sexes improved swim speed in both the $200 \mathrm{~m}$ and $400 \mathrm{~m}$ individual medley and freestyle across the years. Swim-speed improvements ranged between $5.1 \%$ and $5.7 \%$ for men and between $3.3 \%$ and $4.4 \%$ for women. The improvements in swim speed were of a similar extent in both the medley and freestyle. Similarly, international

Table 3 Change in sex difference in swim speed at national and world championships from 1994 to 201 I

\begin{tabular}{lccc}
\hline & \multicolumn{2}{c}{$\begin{array}{l}\text { Mean sex } \\
\text { difference (\%) }\end{array}$} & Significance* \\
\cline { 2 - 3 } & \multicolumn{2}{l}{ I994 20 I I } & \\
\cline { 1 - 2 } National championships & & \\
200 m freestyle & 8.8 & 10.7 & $P<0.0$ I \\
400 m freestyle & 7.8 & 9.4 & $P<0.01$ \\
200 m medley & 8.8 & 9.7 & $P>0.05$ \\
400 m medley & 7.3 & 8.6 & $P<0.01$ \\
World championships & & \\
200 m freestyle & 7.0 & 10.1 & $P>0.05$ \\
400 m freestyle & 9.5 & 9.0 & $P>0.05$ \\
200 m medley & 11.0 & 11.1 & $P>0.05$ \\
400 m medley & 10.2 & 9.4 & $P>0.05$ \\
\hline
\end{tabular}

Note: *Significance refers to linear regression analysis of mean sex difference in swim speed across years.

Abbreviation: $\mathrm{m}$, meters. 
A

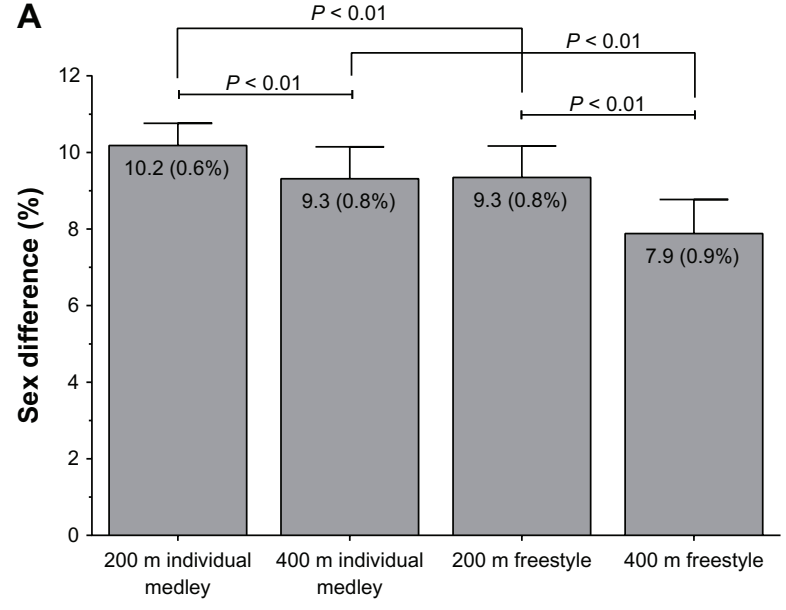

B

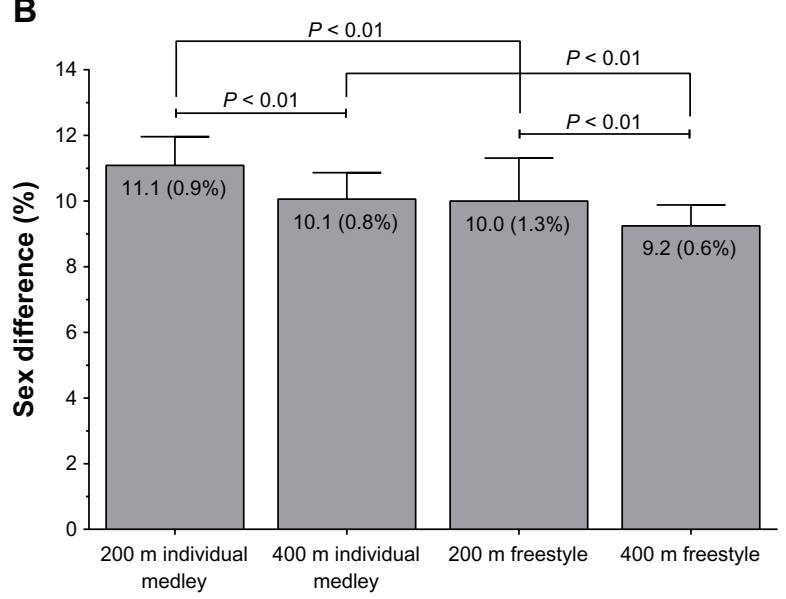

Figure 5 Sex difference in swim speed for the top ten elite Swiss $(\mathbf{A})$ and for the top eight world championship (B) freestyle and individual medley swimmers for $200 \mathrm{~m}$ and $400 \mathrm{~m}$ over the 1994-201 I period.

elite athletes competing in the finals in the world championships improved swim speed in both the $200 \mathrm{~m}$ and $400 \mathrm{~m}$ individual medley across the years. In freestyle, both sexes improved swim speed in the $400 \mathrm{~m}$ across the years, but only men improved in the $200 \mathrm{~m}$ freestyle. The swim-speed improvements in world championships ranged between $2.6 \%$ and $4.6 \%$ in men and up to $4.3 \%$ for women.

We assume that the improvements in performance in the world championships may be lower compared to national championships. A study compared national and international elite swimmers and showed that international swimmers had higher energetic and biomechanical capacity than national swimmers. ${ }^{16}$ Another study concluded that the maximum physiologically possible human frontier may almost be reached, because world record progression has flattened. ${ }^{1}$ We assume, therefore, that swim-speed performance in international elite athletes cannot improve as much as in national elite athletes, because international swimmers may be closer to the maximum physiologically possible human frontier. ${ }^{1}$ Individual medley is a more complex style than freestyle, because the race contains all four strokes within one race. It has been shown that breaststroke was the most important stroke in the medley in determining the race time, followed by backstroke, butterfly, and freestyle. ${ }^{17}$ In another study, backstroke correlated most with the final performance in the $200 \mathrm{~m}$ individual medley for both sexes. ${ }^{18}$ However, further investigation is necessary to quantify these differences more exactly in swim-speed improvement in the four medley strokes.

Lätt et al investigated the relationships between performance and biomechanical, anthropometrical, and physiological parameters in $100 \mathrm{~m}$ freestyle swimming. ${ }^{19}$ The study showed significant correlations between performance and biomechanical aspects, such as stroke rate and stroke index; physiological parameters, such as blood lactate accumulation; and anthropometrical variables, such as body height, bone mass, spine bone mineral density, and arm span. Another study investigated body height and body weight in children aged between 6 and 17 years during the twentieth century. During the period of the study, body height increased between 1 and $2 \mathrm{~cm}$ per decade, and body weight increased between 0.5 and $1.5 \mathrm{~kg}$ per decade. ${ }^{20} \mathrm{~A}$ further study predicted that the fastest athletes will become heavier and taller in future, because the mean height of champion swimmers in the $100 \mathrm{~m}$ freestyle had increased by $11.4 \mathrm{~cm}$ since $1912 .{ }^{21}$ Further investigations would be necessary to analyze anthropometrical changes in swimmers originating from Switzerland across the period of the study.

Apart from changes in anthropometric characteristics, ${ }^{19}$ improvements in training, ${ }^{22}$ physiological variables, ${ }^{19}$ psychological aspects, ${ }^{23}$ and sports nutrition, ${ }^{24}$ developments in material science, ${ }^{9}$ such as the new generations of swimsuits, may also have had an effect on swim speed during this time period. ${ }^{9}$ Berthelot et al showed a gain in swim speed between 2000 and 2009 between $\sim 1.9 \%$ and $\sim 2.6 \%$ in men, and between $\sim 1.3 \%$ and $\sim 2.3 \%$ in women. ${ }^{9}$ In the $200 \mathrm{~m}$ distance, the swim-speed improvements tended to be higher in the medley than in the freestyle for both sexes, which is in line with present findings for women. The improvements due to wearing new swimsuits were related to a gain in buoyancy and drag reduction, ${ }^{25,26}$ a decrease in oxygen uptake, ${ }^{27,28}$ and minute ventilation. ${ }^{28}$ Wearing a wetsuit was allowed in Swiss competitions during the period of the study, even though the wetsuits had no Fédération Internationale de Natation 
(FINA) approval label. More restrictive rules were given for national championships, and even more so for FINA competitions. ${ }^{29}$ From January 1, 2010, FINA prohibited the wearing of full-body wetsuits. ${ }^{30}$ However, this prohibition for wetsuits seemed not to impair swim-speed performance, perhaps partially because FINA authorized the use of the new angled starting blocks with an extended length of the platform and a higher angled surface to ground. ${ }^{31}$ Two recent studies compared the starting performance of the new angled starting block compared to the traditional starting block and concluded that the new kick start was significantly faster than the older grab start. ${ }^{32,33}$

\section{Changes in sex difference in swim performance across the years}

The sex difference in swim speed in elite Swiss swimmers in the $200 \mathrm{~m}$ individual medley was unchanged at $\sim 10.2 \%$, while it increased to values between $8.6 \%$ and $10.7 \%$ in freestyle and the $400 \mathrm{~m}$ medley, respectively. The sex differences in world championships were unchanged between $9.2 \%$ and $11.1 \%$ for both the $200 \mathrm{~m}$ and $400 \mathrm{~m}$ medley and freestyle, respectively. A study on the US Masters Swimming Championships between 1991 and 1995 reported a decrease in the sex differences with increasing race distances, which is in line with our results. ${ }^{34}$ The sex difference in freestyle swimming was $19 \%$ for $50 \mathrm{~m}$ and decreased to $11 \%$ for $1500 \mathrm{~m}$. Another study investigated the sex difference in the $3.8 \mathrm{~km}$ swim in Ironman triathlons between 2006 and 2008 and reported a sex difference of $\sim 12 \%$. ${ }^{35}$ Interestingly, a previous study investigating the $26.4 \mathrm{~km}$ open-water ultraswim Marathon Swim in Lake Zurich, held in Switzerland between 1987 and 2011, showed no sex difference in performance between women and men. ${ }^{12}$ Similarly, another study investigating the 32 km English Channel Swim between England and France between 1900 and 2010 found no sex difference in the mean swimming time of the successful swimmers. ${ }^{13}$

The decrease in sex difference with increasing swim distance may be explained by the positive correlation between upper-body power and freestyle swimming in $50 \mathrm{~m}$ time trials up to $400 \mathrm{~m}$ distances. ${ }^{36}$ However, the correlation generally decreased with increasing race distance. ${ }^{36}$ This might be a reason why the sex difference was higher in the $200 \mathrm{~m}$ short-distance races, because men were found to have significantly greater muscle power than women. ${ }^{37}$ Another study showed that women had a lower energy cost of swimming in freestyle, which could be an advantage in the longer distances compared to men. The higher swim economy in women was due to a different distribution of body density and surface area compared to men, which results in lower underwater torque in women. ${ }^{38}$

An analysis of the $100 \mathrm{~m}, 200 \mathrm{~m}$, and $400 \mathrm{~m}$ freestyle swimming world records from 1957 to 2006 showed a stable sex difference at $11 \%$ for the $100 \mathrm{~m}, 10 \%$ for the $200 \mathrm{~m}$, and $9 \%$ for the $400 \mathrm{~m}$ freestyle. ${ }^{2}$ This study is in line with the present findings of a stable sex difference in world championships. The fact that the sex difference in the $400 \mathrm{~m}$ medley, $200 \mathrm{~m}$, and $400 \mathrm{~m}$ freestyle increased across the years while the sex difference in the $200 \mathrm{~m}$ medley remained unchanged in Swiss championships might be due to the introduction of the new generations of Fastskin suits, which was followed by significant gain in swim-speed performance in the years 2000, 2008, and 2009. ${ }^{9}$ In the $200 \mathrm{~m}$ medley, both sexes showed a similar gain in swim speed, while men had a higher gain in swim speed in the $400 \mathrm{~m}$, the $200 \mathrm{~m}$, and the $400 \mathrm{~m}$ freestyle. ${ }^{9}$ Further investigation would be necessary to clarify the unstable sex difference in Swiss championships compared to the stable sex difference in world championships. We assume that there might be a higher fluctuation in annual swim-speed performance at the national level compared to the international level, because of the lower number of athletes at the international level and therefore lower selection pressure.

\section{Sex difference in freestyle and medley}

The mean sex difference during the 1994-2011 period was lower in the $400 \mathrm{~m}$ events than in the $200 \mathrm{~m}$ for both medley and freestyle in Swiss and world championships. Furthermore, the sex difference was lower in freestyle than medley in the same distances. We presume that the lower sex difference in freestyle compared to the medley has multifactorial causes. It has been shown that freestyle was the most economic swimming stroke, followed by backstroke, butterfly and breaststroke. ${ }^{39}$ In another study, women had higher swim economy than men in freestyle because of lower underwater torque due to a different distribution of body density. ${ }^{38}$ Women might benefit more from their lower energy cost in swimming freestyle, the most economic swim stroke. As discussed before, men were found to have more muscle mass than women, ${ }^{37}$ and upper-body power was positively correlated with freestyle swim-speed performance up to $400 \mathrm{~m} .{ }^{36}$ We assume that the four changes of stroke during medley races may be an advantage for men, because different muscle groups can be used after the stroke changes during the medley races, and this may result in an advantage over short-distance races due to the higher muscle mass in men. 
However further investigation is needed to explain the sex difference in freestyle and medley.

\section{Conclusion}

These results showed that female and male swimmers at the national level originating from Switzerland and international elite athletes in world championships improved swim speed in the freestyle and individual medley in the $200 \mathrm{~m}$ and the $400 \mathrm{~m}$ from 1994 to 2011, with the exception of women in the $200 \mathrm{~m}$ freestyle at the world championships. The sex difference in swim speed in elite swimmers at national level in the $200 \mathrm{~m}$ medley was unchanged, while it increased in the freestyle and $400 \mathrm{~m}$ medley across years. At the world championships, the sex difference was unchanged in both distances and disciplines. At national and international level, the sex difference in performance in the $200 \mathrm{~m}$ medley was higher than in the $400 \mathrm{~m}$ medley and freestyle. Furthermore, the sex difference was lower in the freestyle compared to the medley over the same distances. The improvements might be related to improvements in training, changes in anthropometric characteristics, and the development of the new swimsuits. Future studies should investigate the trend in swim speed and the sex difference in other strokes. Furthermore, the reasons for a greater sex difference in the medley than the freestyle should be investigated.

\section{Disclosure}

The authors report no conflicts of interest in this work.

\section{References}

1. Berthelot G, Thibault V, Tafflet M, et al. The citius end: world records progression announces the completion of a brief ultra-physiological quest. PLoS One. 2008;3(2):e1552.

2. Nevill A, Whyte G, Holder R, Peyrebrune M. Are there limits to swimming world records? Int J Sports Med. 2007;28(12):1012-1017.

3. Lippi G, Banfi G, Favaloro E, Rittweger J, Maffulli N. Updates on improvement of human athletic performance: focus on world records in athletics. Br Med Bull. 2008;87(1):7-15.

4. Thibault V, Guillaume M, Berthelot G, et al. Women and men in sport performance: the gender gap has not evolved since 1983. J Sports Sci Med. 2010;9(2):214-223.

5. Lepers R. An analysis of Hawaii Ironman performances in elite triathletes from 1981 to 2007. Med Sci Sports Exerc. 2008;40(19):1828-1834.

6. Whipp B, Ward S. Will women soon outrun men? Nature. 1992; 355(6355):25.

7. Beneke R, Leithäuser RM, Doppelmayr M. Women will do it in the long run. Br J Sports Med. 2005;39(7):410.

8. Seiler S, De Koning J, Foster C. The fall and rise of the gender difference in elite anaerobic performance 1952-2006. Med Sci Sports Exerc. 2007;39(3):534-540.

9. Berthelot G, Len S, Hellard P, et al. Technology and swimming: 3 steps beyond physiology. Mater Today (Kidlington). 2010;13(11):46-51.

10. Colwin C. Looking back, looking ahead. In: McEntire C, Hawkins S, Wentworth J, editors. Breakthrough Swimming. Champaign (IL): Human Kinetics; 2002:217-228.
11. Smith D, Norris S, Hogg J. Performance evaluation of swimmers: scientific tools. Sports Med. 2002;32(9):539-554.

12. Eichenberger E, Knechtle B, Knechtle P, et al. Sex difference in openwater ultra-swim performance in the longest freshwater lake swim in Europe: sex difference in ultra-swimming. J Strength Cond Res. Epub June 28, 2012.

13. Eichenberger E, Knechtle B, Knechtle P, Rüst C, Rosemann T, Lepers R. Best performances by men and women open-water swimmers during the 'English Channel Swim' from 1900 to 2010. J Sports Sci. 2012;30(12):1295-1301.

14. Fédération Suisse de Natation (FSN). Rekorde/Bestenlisten. Available from: http://rankings.fsn.ch. Accessed May 7, 2012.

15. SwimRankings.net [homepage on the Internet]. Veranstaltungen. Available from: http://www.swimrankings.net/index.php?page= meetSelect. Accessed December 1, 2012.

16. Costa M, Bragada J, Mejias J, et al. Tracking the performance, energetics and biomechanics of international versus national level swimmers during a competitive season. Eur J Appl Physiol. 2012;112(3):811-820.

17. Mason B, Cossor J. What can we learn from competition analysis at the 1999 Pan Pacific Swimming Championships? In: Hong Y, Johns DP, Sanders R, editors. Proceedings of the 18th International Symposium on Biomechanics in Sports; June 25-30, 2000; Hong Kong, China. Hong Kong: Chinese University Press; 2000:75-82.

18. Saavedra J, Escalante Y, Garcia-Hermoso A, Arellano R, Navarro F. A twelve-year analysis of pacing strategies in 200- and 400-m individual medley in international swimming competitions. $J$ Strength Cond Res. 2012;26(12):3289-3296.

19. Lätt E, Jürimäe J, Mäestu J, et al. Physiological, biomechanical and anthropometrical predictors of sprint swimming performance in adolescent swimmers. J Sports Sci Med. 2010;9:398-404.

20. Kagawa M, Tahara Y, Moji K, Nakao R, Aoyagi K, Hills A. Secular changes in growth among Japanese children over 100 years (1900-2000). Asia Pac J Clin Nutr. 2011;20(2):180-189.

21. Charles J, Bejan A. The evolution of speed, size and shape in modern athletics. J Exp Biol. 2009;212(Pt 15):2419-2425.

22. Issurin V. New horizons for the methodology and physiology of training periodization. Sports Med. 2010;40(3):189-206.

23. Psychountaki M, Zervas Y. Competitive worries, sport confidence, and performance ratings for young swimmers. Percept Mot Skills. 2000; 91(1):87-94.

24. Stellingwerff T, Maughan R, Burke L. Nutrition for power sports: middle-distance running, track cycling, rowing, canoeing/kayaking, and swimming. J Sports Sci. 2011;29(1):79-89.

25. Mollendorf J, Termin A, Oppenheim E, Pendergast D. Effect of swim suit design on passive drag. Med Sci Sports Exerc. 2004;36(6): 1029-1035.

26. Tomikawa M, Nomura T. Relationships between swim performance, maximal oxygen uptake and peak power output when wearing a wetsuit. J Sci Med Sport. 2009;12(2):317-322.

27. Chatard JC, Wilson B. Effect of fastskin suits on performance, drag, and energy cost of swimming. Med Sci Sports Exerc. 2008;40(6): $1149-1154$.

28. Trappe T, Pease D, Trappe S, Troup J, Burke E. Physiological responses to swimming while wearing a wet suit. Int J Sports Med. 1996;17(2): $111-114$

29. Fédération Suisse de Natation (FSN). Die Regeln der FINA für Wettkämpfe im Schwimmen. Available from: http://www.fsn.ch/ Portaldata/1/Resources/dokumente/reglemente/swimming/731-d.pdf. Accessed May 7, 2012.

30. Fédération Internationale de Natation (FINA). PR59 - FINA bureau meeting. Available from: http://www.fina.org/project/index. php?option=com_content $\&$ task=view \&id=2543\&Itemid $=107$. Accessed May 7, 2012.

31. Omega. FINA approves new OMEGA start blocks for official swimming competitions [press release]. Biel/Bienne, Switzerland: Omega; April 23, 2008. Available from: http://www.omegawatches.com/press/ press-release-detail/978. Accessed May 23, 2012. 
32. Biel K, Fischer S, Kibele A. Kinematic analysis of take-off performance in elite swimmers: new OSB11 versus traditional starting block. In: Kjendlie P, Stallman R, Cabri J, editors. Proceedings of the 11th International Symposium for Biomechanics and Medicine in Swimming; June 16-19, 2010; Oslo, Norway.

33. Honda K, Sinclair P, Mason B, Pease D. A biomechanical comparison of elite swimmers start performance using the traditional track start and the new kick start. In: Kjendlie P, Stallman R, Cabri J, editors. Proceedings of the 11th International Symposium for Biomechanics and Medicine in Swimming; June 16-19, 2010; Oslo, Norway.

34. Tanaka H, Seals D. Age and gender interactions in physiological functional capacity: insight from swimming performance. J Appl Physiol. 1997;82(3):846-851.

35. Lepers R, Maffiuletti N. Age and gender interactions in ultra-endurance performance: insight from triathlon. Med Sci Sports Exerc. 2011;43(1): $134-139$.
36. Hawley J, Williams M. Relationship between upper body anaerobic power and freestyle swimming performance. Int J Sports Med. 1991; 12(1): $1-5$.

37. Gursoy R. Sex differences in relations of muscle power lung function, and reaction time in athletes. Percept Mot Skills. 2010;110(3): 714-720.

38. Pendergast D, DiPrampero P, Craig A, Wilson D, Rennie D. Quantitative analysis of the front crawl in men and women. J Appl Physiol. 1977; 43(3):475-479.

39. Barbosa T, Fernandes R, Keskinen K, et al. Evaluation of the energy expenditure in competitive swimming strokes. Int J Sports Med. 2006; 27(11):894-899.

\section{Publish your work in this journal}

Open Access Journal of Sports Medicine is an international, peer-reviewed, open access journal publishing original research, reports, reviews and commentaries on all areas of sports medicine. The manuscript management system is completely online and includes a very quick and fair peer-review system.
Visit http://www.dovepress.com/testimonials.php to read real quotes from published authors. 